\title{
16S rRNA Gene Sequence Analysis of Snow Leopard, Gray Wolf, Horse and Bactrian Camel in Mongolia
}

\author{
Munkhtuul Tsogtgerel ${ }^{1}$, Munkhtogtokh Baljijjnyam², Nansalmaa Suren ${ }^{3}$ and Lkhagvasuren Sodnom ${ }^{4}$ \\ 1. School of Veterinary Medicine, Mongolian University of Life Sciences (MULS), Zaisan 17024, Ulaanbaatar, Mongolia \\ 2. Research Institute of Animal Husbandry, Mongolian University of Life Sciences (MULS), Zaisan 17024, Ulaanbaatar, Mongolia \\ 3. School of Engineering, Mongolian University of Life Sciences (MULS), Zaisan 17024, Ulaanbaatar, Mongolia \\ 4. Institute of Veterinary Medicine, Mongolian University of Life Sciences (MULS), Zaisan 17024, Ulaanbaatar, Mongolia
}

\begin{abstract}
In this study, mitochondrial 16S rRNA sequences of snow leopard, gray wolf, domestic horse and Bactrian camel inhabited or domesticated in Mongolian territory were obtained by using polymerase chain reaction (PCR) based on universal primers for 16S rRNA (F-5'-AACGAGCCTGGTGATA-3' and R-5'-CTCCGGTCTGAACTCAGATCACGTA-3'). The 16S rRNA sequence was 1,048 bp to 1,086 bp in length, and each sequence was compared to other related species (Felidae, Camelidae, Equidae and Canidae) by using NCBI Basic Local Alignment Search Tool (BLAST). Results showed that sequences were highly similar to sequences in GenBank database (93\%-99\%). Then phylogenetic analysis was performed based on about 1,100 bp sequence of $16 \mathrm{~S}$ rRNA for Panthera uncia, Canis lupus, Equus caballus, Camelus bactrianus and other related species. The result revealed that $P$. uncia and $P$. leo were sister species, $C$. bactrianus and $C$. ferus were more closely related species, and wolf and dog were the almost similar species. This finding could be important for designing species specific primers for PCR based analysis of animal species identification and forensic veterinary medicine.
\end{abstract}

Key words: 16S rRNA gene, sequence analysis, snow leopard, gray wolf, horse, Bactrian camel.

\section{Introduction}

The identification of animal species is critically important for solving a number of issues that can be arisen in various areas, such as religious and traditional ethics (special interest), health (allergic individuals), economy (fair trade), jurisdictions, forensic veterinary medicine and food safety.

In the last few years, illegal actions, including livestock theft, meat adulteration and fraud meat labeling, making meal with dog and cat meat, endangered animals’ meat export, and selling illegally hunted animal meat, are reported in Mongolia.

Snow leopard (Panthera uncia) is listed as endangered on the IUCN Red List of Threatened Species [1] and the Convention on International Trade of Endangered Species (CITES) [2]. Gray wolf (Canis

Corresponding author: Lkhagvasuren Sodnom, Ph.D., research field: food safety and hygiene. lupus) is also listed in the CITES [2]. The distribution of Bactrian camel is very limited, and they are only reared in Mongolia, China, Kazakhstan and Kyrgyzstan. In Mongolia, the camel population numbered 559,000 in 1985, and the number of camels has decreased significantly and fell to 277,100 in 2009 [3]. Furthermore, researchers are highly interested in study about phylogenetic relationship between Mongolian domestic Bactrian camel (Camelus bactrianus) and Mongolian wild Bactrian camel (Camelus ferus) which is listed as critically endangered on the IUCN Red List of Threatened Species [1].

Since 2015, there are a number of requests from countryside people and police organization for identification of meat species from these endangered animals, because people illegally export those species of game meat to China. As well as, there are also complaints that people illegally hunt Mongolian wild 
ass (Equus hemionus hemionus) and sell its meat as a horse meat (Equus caballus).

Meat inspectors need reliable and sensitive techniques to identify meat species when meat is cut, deboned, deformed or processed. These frauds are difficult to detect with protein-based methods of species identification [4]. The nucleic acid based analytics has already been widely used in many fields [4-6]. So that, there is a need to do DNA sequencing analysis of both endangered and domestic species and elaborate identification method based on DNA.

Mitochondrial DNA sequences are the most common resource currently used for species identification and estimating phylogenetic relationships among animal taxa [7-12]. The reason is that firstly most cells have many mitochondria, secondly mutation rate is high, and thirdly limit of detection (LOD) is low [13]. Among mitochondrial genes, cytB, D-loop, 12S and 16S rRNA have been used for species identification [3, 13].

In this study, the mitochondrial 16S rRNA of snow leopard, gray wolf, domestic horse and Bactrian camel in Mongolia were sequenced and compared with 16S rRNA sequences taken from GenBank by performing phylogenetic tree.

\section{Materials and Methods}

Meat samples used in the sequence analysis were taken from species originated from Ulaanbaatar city (E. caballus), Umnugovi province (C. bactrianus and Canis lupus) and Khentii province (C. lupus), repectively. The polymerase chain reaction (PCR) products of 1,048-1,086 bp long were sequenced from four samples of Mongolian horse (E. caballus), Bactrian camel (C. bactrianus), Snow leopard ( $P$. uncia) and gray wolf (C. lupus).

\subsection{DNA Isolation}

For DNA isolation, phenol-chloroform method and FavorPrep tissue DNA extraction kit according to producer guide were used. First, $1 \mathrm{~g}$ of meat was cut into small pieces. The tissue was homogenized by mortar and pestle with liquid nitrogen. The homogenate was then transferred to $1.5 \mathrm{~mL}$ tube, added $500 \mu \mathrm{L}$ of lysis buffer (0.1 M Tris- $\mathrm{HCl}$ (pH 8.0), 1\% SDS, $0.1 \mathrm{M} \mathrm{NaCl}, 10 \mathrm{mM}$ EDTA) and $8 \mu \mathrm{L}$ proteinase $\mathrm{K}$. The suspension was gently vortexed and incubated for $7 \mathrm{~h}$ at $65^{\circ} \mathrm{C}$. Then samples were treated with phenol/chloroform ( $500 \mu \mathrm{L})$, then centrifuged at $15,000 \mathrm{rpm}$ for $10 \mathrm{~min}$. The supernatant was put into new tube and added 1,000 $\mu \mathrm{L} 99 \%$ ethanol and $30 \mu \mathrm{L}$ $3 \mathrm{M} \mathrm{NaCl}$, and incubated at $25-30{ }^{\circ} \mathrm{C}$ for $20 \mathrm{~min}$. Then it was centrifuged at $15,000 \mathrm{rpm}$ for $15 \mathrm{~min}$ at $4{ }^{\circ} \mathrm{C}$, the supernatant dumped and $400 \mu \mathrm{L} \quad 70 \%$ ethanol added into the pellet and centrifuged at 15,000 rpm for $5 \mathrm{~min}$ at $4{ }^{\circ} \mathrm{C}$. Again the supernatant was dumped and the DNA extract was dried for 10-15 min in the air. Then dried DNA was dissolved in $50 \mu \mathrm{L}$ of ultrapure water. DNA samples were stored at $-20{ }^{\circ} \mathrm{C}$.

\subsection{PCR Amplification}

To amplify 16S rRNA (1,100 bp), F-5'-AACGAGCCTGGTGATA-3' and R-5'-CTCCGGTCTGAACTCAGATCACGTA-3' primers [14] were used for PCR.

Each PCR amplification reaction was a volume of 25 $\mu \mathrm{L}$ with approximately $800 \mathrm{ng}$ of template DNA $(1 \mu \mathrm{L})$, 10× PCR buffer (with $\mathrm{MgCl}_{2}$ ) $2.5 \mu \mathrm{L}$, dNTP $2.0 \mu \mathrm{L}$, each primer $1 \mu \mathrm{L}$ and Taq DNA polymerase $0.2 \mu \mathrm{L}$.

PCR amplification was carried out by using a thermal cycle as follows: preheating $94{ }^{\circ} \mathrm{C}$ for $7 \mathrm{~min}$, 30-35 cycles of $94^{\circ} \mathrm{C}$ for $1 \mathrm{~min}$ (denaturation), $56{ }^{\circ} \mathrm{C}$ for 1 min (elongation), $72{ }^{\circ} \mathrm{C}$ for $45 \mathrm{~s}$ (extension) and a final extension of $72{ }^{\circ} \mathrm{C}$ for $5 \mathrm{~min}$ (Fig. 1). PCR products were analyzed by gel electrophoresis in $1.5 \%$ agarose gel with ethidium bromide staining.

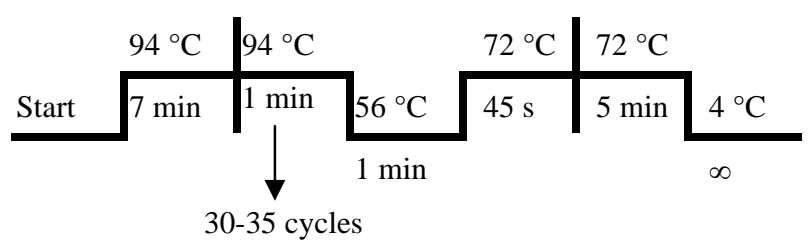

Fig. 1 PCR cycle for 16S rRNA. 


\subsection{Sequencing Analysis}

Nucleotide sequence of the 16S rRNA gene was determined by the Big-Dye Terminator method on an ABI PRISM 3100 automated sequencer.

In order to assemble sequence data, Codon Code Aligner software was used to make contig sequence. The 16S rRNA sequence was directly submitted to DDBJ Nucleotide Sequence Submission System (NSSS).

Alignment analysis and phylogenetic tree for $16 \mathrm{~S}$ rRNA sequence of those species (Table 1) were analyzed by ClustalX2, MEGA6 and NCBI Basic Local Alignment Search Tool (BLAST) software [15]. Maximum likelihood method was used for constructing phylogenetic tree.

\section{Results and Discussion}

Approximately 1,100 bp of 16S rRNA gene from Mongolian domestic horse (E. caballus), Bactrian camel (C. bactrianus), snow leopard (P. uncia) and gray wolf (C. lupus) were amplified (Fig. 2), sequenced and reported on the DDJB/EMBL/GenBank database with following accession numbers: LC147065, LC147066, LC147067 and LC147068, respectively (Table 2).

Universal primers designed by Lkhagvasuren and Amarsaikhan [14] could be used for mitochondrial 16S rRNA gene amplification in a sequence analysis of four animal mitochondrial genomes (Fig. 2).

\subsection{Sequence Analysis of Snow Leopard}

A search of the nucleotide database using the BLAST revealed that sequence of snow leopard ( $P$. uncia) has 98\% sequence identity with 16S rRNA sequence from snow leopard (EF551004), 97\% identical with white African lion (KF907306), 96\% identical with tiger (EF551003) and 95\% identical with domestic cat (U20753). Alignment analysis revealed that it was different from African lion by 33 nucleotides, tiger by 35 nucleotides, domestic cat by 52
Table 1 Species and accession numbers of mitochondrial $16 \mathrm{~S}$ rRNA sequences used in this study.

\begin{tabular}{|c|c|}
\hline Species & Accession No. \\
\hline \multicolumn{2}{|l|}{ Felidae species (5) } \\
\hline Panthera uncia* & LC147065 \\
\hline Uncia uncia ${ }^{*}$ & EF551004 \\
\hline Panthera leo leo & KF907306 \\
\hline Panthera tigris & EF551003 \\
\hline Felis catus & U20753 \\
\hline Lynx lynx & KM982549 \\
\hline \multicolumn{2}{|l|}{ Equudae species (4) } \\
\hline Equus caballus & LC147067 \\
\hline Equus caballus & HQ439500 \\
\hline Equus caballus & HQ439499 \\
\hline Equus caballus & AY584828 \\
\hline Equus przewalskii & HQ439484 \\
\hline Equus hemionus & NC016061 \\
\hline Equus asinus & KT182635 \\
\hline \multicolumn{2}{|l|}{ Camelidae species (4) } \\
\hline Camelus bactrianus & LC147066 \\
\hline Camelus bactrianus & KX554930 \\
\hline Camelus ferus & EF507800 \\
\hline Camelus dromedarius & KU605078 \\
\hline Lama pacos & Y19184 \\
\hline \multicolumn{2}{|l|}{ Canidae species (2) } \\
\hline Canis lupus & LC147068 \\
\hline Canis lupus & KU696399 \\
\hline Canis lupus & KU696395 \\
\hline Canis lupus familiaris & EU408300 \\
\hline Canis lupus & KU644671 \\
\hline
\end{tabular}

Panthera uncia and Uncia uncia are the same species.

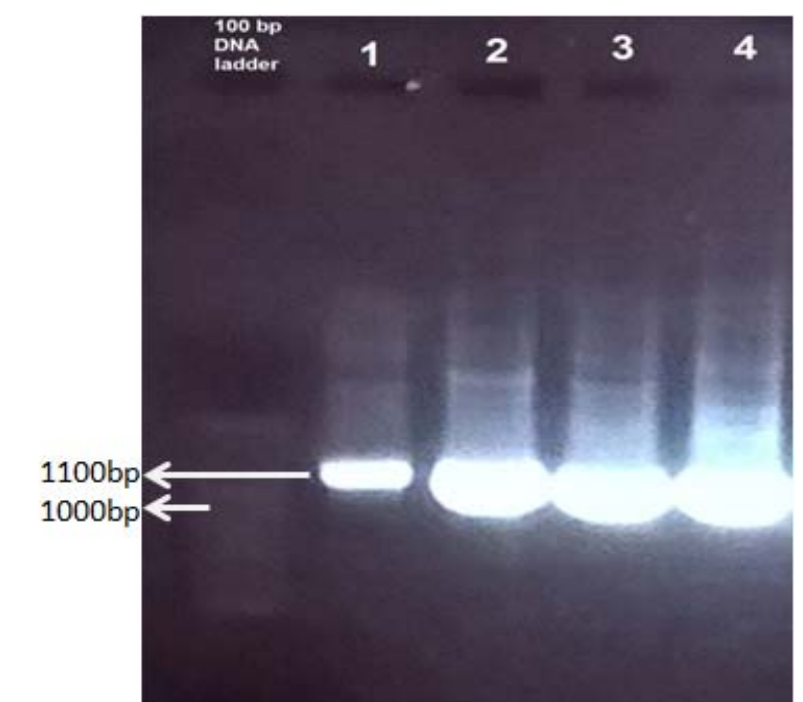

Fig. 2 PCR amplicons in the mitochondrial 16S rRNA gene from DNA samples, including leopard (1), wolf (2), camel (3) and horse (4) samples. 

and Bactrian Camel in Mongolia

Table 2 List of DNA sequences submitted to GenBank.

\begin{tabular}{lll}
\hline No. & Animal species & $\begin{array}{l}\text { Accession number in } \\
\text { GenBank }\end{array}$ \\
\hline 1 & Panthera uncia & LC147065 \\
2 & Camelus bactrianus & LC147066 \\
3 & Equus caballus & LC147067 \\
4 & Canis lupus & LC147068 \\
\hline
\end{tabular}

nucleotides and Lynx lynx by 62 nucleotides. Alignment result indicates that it is possible to design primers which differentiate $P$. uncia from $F$. catus.

\subsection{Sequence Analysis of Bactrian Camel}

The 1,048 bp partial nucleotide sequence of the 16S rRNA gene from Mongolian camel (C. bactrianus) showed 99\% homology to the Bactrian camel (KX554930), 97\% identical with Arabian camel (KU605080) and 93\% identical with Lama pacos (Y19184). According to alignment analysis by Clustal X2, it was different from wild Bactrian camel by three nucleotides, dromedary camel by 25 nucleotides and Lama pacos by 65 nucleotides. Due to difference of only three nucleotides, it is impossible to design PCR primers which differentiate domestic Bactrian camel from wild Bactrian camel. But PCR-RFLP analysis could be used for identifying the species.

\subsection{Sequence Analysis of Mongolian Horse}

The 1,063 bp partial nucleotide sequence of the 16S rRNA gene from Mongolian horse (E. caballus) showed 99\% homology to the Russian horse (KT757759) of Urals, as well as Takhi (E. przewalskii
KT368750). And Clustal X2 alignment analysis showed that it was different from Vladimir heavy draft horse by seven nucleotides, Takhi by six nucleotides, Welsh pony by nine nucleotides, Jeju native horse by 14 nucleotides, Khulan (wild ass) by 47 nucleotides and donkey by 51 nucleotides. This result showed that specific primer for Mongolian native breed horse which differentiates it from Mongolian wild ass could be designed based on the 16s rRNA sequence.

\subsection{Sequence Analysis of Mongolian Gray Wolf}

The 1,063 bp partial nucleotide sequence of the 16S rRNA gene from Mongolian gray wolf (C. lupus) showed 99\% homology to the Bulgarian gray wolf (KU696399), as well as 99\% identical with Tibetan mastiff breed dog (EU408300). As a result of alignment analysis, it had 1-2 nucleotides difference from Bulgarian wolf, Iranian wolf and Tibetan Mastiff breed dog. It means it is not possible to design Mongolian gray wolf specific primer for amplifying 16S rRNA sequence by PCR.

\subsection{Phylogenetic Tree Analysis}

The phylogenetic tree, based on 16S rRNA sequences of Felidae species, was constructed using snow leopard, African lion, tiger and domestic cat, with grey wolf as an outgroup (Fig. 3). The result indicated that $P$. uncia and $P$. leo were the sister species, which was similar to the study result of Wei et al. [12].

The phylogenetic tree, based on 16S rRNA sequences

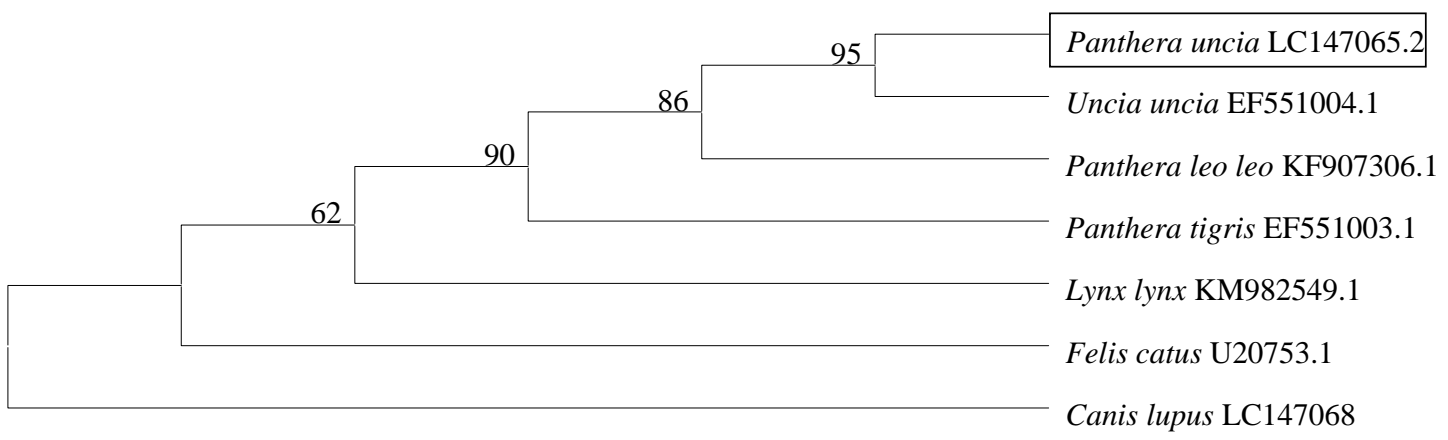

Fig. 3 Phylogenetic tree showing genetic relationship of Pantheria uncia with other Felidae species based on 1,086 bp length of $16 \mathrm{~S}$ rRNA sequences (maximum likelihood method). 


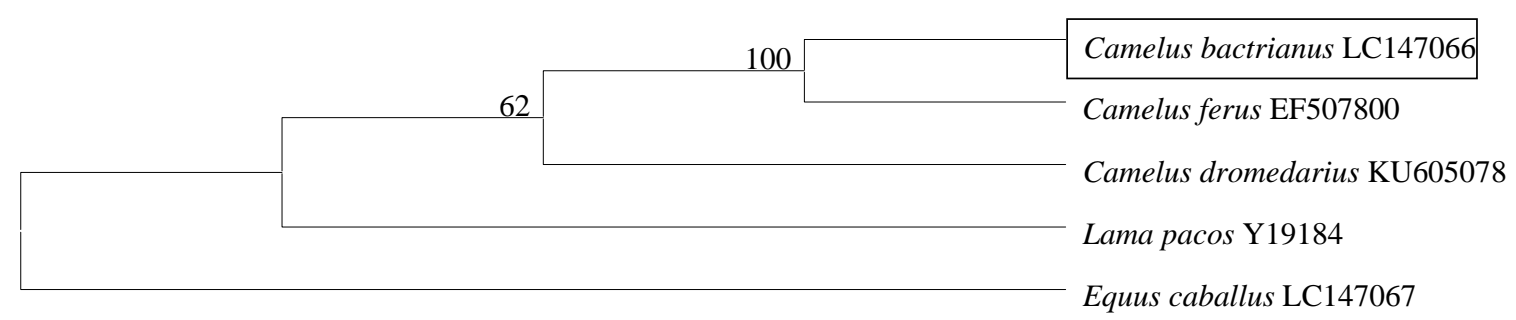

Fig. 4 Phylogenetic tree showing genetic relationship of Camelus bactrianus with other Camelidae species based on 1,048 bp length of 16S rRNA sequences (maximum likelihood method).

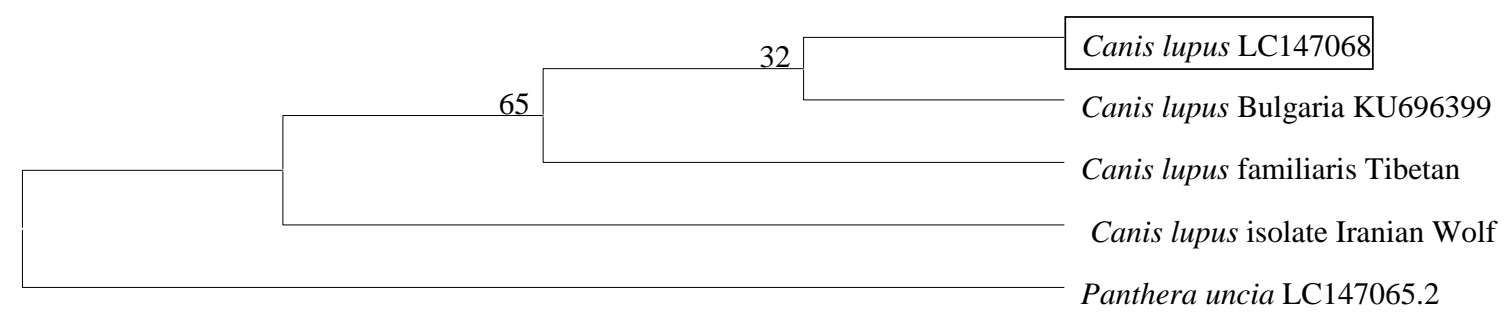

Fig. 5 Phylogenetic tree showing genetic relationship of Canis lupus with other Canidae species based on 1,063 bp length of 16S rRNA sequences (maximum likelihood method).

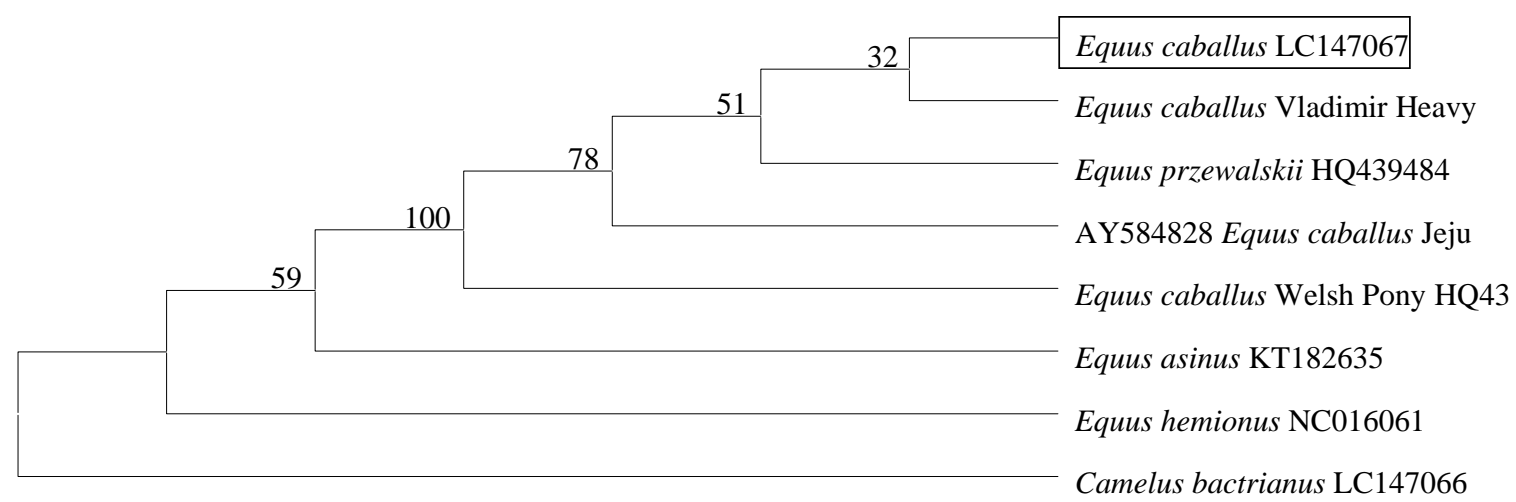

Fig. 6 Phylogenetic tree showing genetic relationship of Equus caballus with other Equidae species based on 1,063 bp length of $16 \mathrm{~S}$ rRNA sequences (maximum likelihood method).

of Camelidae species, was constructed using Mongolian Bactrian camel, Mongolian wild Bactrian camel, Arabian dromedary camel and Lama paco, with Mongolian horse as an outgroup (Fig. 4). The phylogenetic tree clearly showed that Mongolian domestic camel is sister group to wild Bactrian camel, and this result is consistent with research results of Ming et al. [11].

On the other hand, Ji et al. [16] concluded that the extant wild camel is a separate lineage, but not the direct progenitor of the domestic Bactrian camel.

The phylogenetic tree, based on 16S rRNA sequences of Canidae species, was constructed using
Mongolian gray wolf, Bulgarian gray wolf, Iranian wolf and Tibetan Mastiff breed dog, with snow leopard as an outgroup (Fig. 5). Result showed that Mongolian gray wolf has close phylogenetic relationship with Bulgarian gray wolf.

The phylogenetic tree, based on 16S rRNA sequences of Equudae species, was constructed using Mongolian domestic horse, Vladimir Heavy draft horse, Takhi, Khulan, donkey, Welsh pony and Jeju native horse, with Bactrian camel as an outgroup (Fig. 6). The result showed that Mongolian domestic horse and Vladimir heavy draft horse are more closely related horse breeds than Jeju native horse breed in 
Korea.

One interesting result is that Przewalskii horse is more closely related to Mongolian native breed horse than E. asinus and E. hemionus.

\section{Conclusions}

In this study, the $16 \mathrm{~S}$ rRNA of $P$. uncia, C. lupus, $C$. bactrianus and E. caballus were sequenced and registered to GenBank database. It can be concluded that Mongolian gray wolf and domestic dog are highly similar by their mitochondrial $16 \mathrm{~S}$ rRNA sequences. $E$. caballus is more closely related to $E$. przewalskii than E. hemionus. C. bactrianus and C. ferus are sister species.

It is assuming that those sequences will be useful genetic resource for other researchers' study, because those species are endangered and may be highly interesting species for phylogenetic study. Sequence of 16S rRNA gene is important genetic resource for identifying animal species, so the sequenced DNAs will be useful for further studies related to forensic veterinary medicine and meat adulteration analysis against illegal hunting of endangered species.

\section{Acknowledgments}

This work was supported by grants from International Foundation for Science (IFS, E/5671-1) in Sweden. The authors are grateful to Dr. Boldbaatar Damdinsuren and Otgonsuren Davaajav, researchers of Laboratory of Food Safety and Hygiene, and Laboratory of Molecular Biology and Genetics, Institute of Veterinary Medicine (IVM), for a number of valuable supports and suggestions on this study.

\section{References}

[1] IUCN. 2017. "The IUCN Red List of Threatened Species.” Accessed August 18, 2017. http://www.iucnredlist.org/.

[2] Convention on International Trade in Endangered Species of Wild Fauna and Flora (CITES). 2017. "Convention on International Trade in Endangered Species of Wild Fauna and Flora Appendices I, II and III.” Accessed April 4, 2017. https://www.cites.org/eng/app/appendices.php.

[3] Mongolian Livestock. 2010. "Mongolian Camel.”
Accessed May 2017. https://mofa.gov.mn/livestock/index.php?option=com_co ntent $\&$ view=category \&layout=blog\&id=50\&Itemid $=82 \&$ lang=en.

[4] Farag, M. R., Alagawany, M., Abd El-Hack, M. E., Tiwari, R., and Dhama, K. 2015. "Identification of Different Animal Species in Meat and Meat Products: Trends and Advances.” Adv. Anim. Vet. Sci. 3 (6): 334-6.

[5] Matsunaga, T., Chikuni, K., Tanabe, R., Muroya, S., Shibata, K., Yamada, J., and Shinmura, Y. 1999. “A Quick and Simple Method for Meat Species and Meat Products by PCR Assay.” Meat Science 51 (2): 143-8.

[6] Pereira, F., Carneiro, J., and Amorim, A. 2008. "Identification of Species with DNA-Based Technology: Current Progress and Challenges.” Recent Patents on DNA \& Gene Sequences 2 (3): 187-200.

[7] Parodi, B., Aresu, O., Bini, D., Lorenzini, R., Schena, F., Visconti, P., Cesaro, M., Ferrera, D., Andreotti, V., and Ruzzon, T. 2002. "Species Identification and Confirmation of Human and Animal Cell Lines: A PCR Based Approach.” Biotechniques 32 (2): 433-40.

[8] Zhang, W. Q., and Zhang, M. H. 2013. "Complete Mitochondrial Genomes Reveal Phylogeny Relationship and Evolutionary History of the Family Felidae.” Genet. Mol. Res. 12 (3): 3256-62.

[9] Kuehn, R., Kaczensky, P., Lkhagvasuren, D., Pietsch, S., and Walzer, C. 2006. "Differentiation of Meat Samples from Domestic Horses (Equus caballus) and Asiatic Wild Asses (Equus hemionus) Using a Species-Specific Restriction Site in the Mitochondrial Cytochrome b Region.” Mongolian J. Biol. Sci. 4 (2): 57-62.

[10] Aggarwal, R. K., Kivisild, T., Ramadevi, J., and Singh, L. 2007. "Mitochondrial DNA Coding Region Sequences Support the Phylogenetic Distinction of Two Indian Wolf Species.” J. Zool. Syst. Evol. Res. 45 (2): 163-72.

[11] Ming, L., Yi, L., Guo, F. C., Siriguleng, S., and Jirimutu, J. 2016. "Molecular Phylogeny of the Bactrian Camel Based on Mitochondrial Cytochrome b Gene Sequences.” Genet. Mol. Res. 15 (3). doi:10.4238/gmr.15038983.

[12] Wei, L., Wu, X. B., and Jiang, Z. G. 2009. "The Complete Mitochondrial Genome Structure of Snow Leopard Panthera uncial.” Mol. Biol. Rep. 36 (5): 871-8.

[13] Ballin, N. Z., Vogensen, F. K., and Karlsson, A. H. 2009. "Species Determination-Can We Detect and Quantify Meat Adulteration?” Meat Science 83 (2): 165-74.

[14] Amarsaikhan, T., and Lkhagvasuren, S., and Boldbaatar, D. 2008. "Polymerase Chain Reaction-Restriction Fragment Length Polymorphism (PCR-RFLP) Analysis for Detection Meat Species.” Presented at Training for Rural Development Project "Sustainable Development through Research and Extension”, 15-24. 


\section{and Bactrian Camel in Mongolia}

[15] Tamura, K., Stecher, G., Peterson, D., Filipski, A., and Kumar, S. 2013. "MEGA6: Molecular Evolutionary Genetics Analysis Version 6.0.” Mol. Biol. Evol. 30 (12) 2725-9.

[16] Ji, R., Cui, P., Ding, F., Geng, J., Gao, H., Zhang, H., Yu,
J., Hu, S., and Meng, H. 2009. "Monophyletic Origin of Domestic Bactrian Camel (Camelus bactrianus) and Its Evolutionary Relationship with the Extant Wild Camel (Camelus bactrianus ferus)." Animal Genetics 40 (4): 377-82. 